\title{
INVESTIGATING BASIC NEEDS SATISFACTION IN THE ELDERLY PEOPLE WITH SOME INDIVIDUAL CHARACTERISTICS BASED ON MODELING AND ROLE- MODELING THEORY
}

\author{
Simin Sharifi ${ }^{1}$, Leila Safabakhsh ${ }^{2}$, Farnoush Khojasteh ${ }^{3}$ \\ ${ }^{1}$ Community Nursing Research Center, Zahedan University of Medical Sciences, Zahedan, Iran. \\ ${ }^{2}$ Community Nursing Research Center, Zahedan University of Medical Sciences, Zahedan, Iran. \\ ${ }^{3}$ Community Nursing Research Center, Zahedan University of Medical Sciences, Zahedan, Iran.
}

\section{ABSTRACT}

\section{BACKGROUND}

Modeling and role modeling theory is one of the applied theories in nursing, which originates from the practice. Basic needs satisfaction is the core concept in this model. Theorists of this theory believe that when basic needs are met and dependence is developed in the individual, he will be able to adapt with the stresses, feel valuable, and mobilize resources for coping with stresses. While if basic needs are not met and confident dependence is not developed in the person, the ability and mobilization of resources for stress coping would be reduced. Since the elderly population is growing in Iran, current research was conducted investigating basic needs satisfaction based on modeling and role-modeling theory and some individual characteristics in the elderly people.

\section{METHODS}

The research population in this descriptive study included all elderly people referring to Kahrizak Charity Institute in Alborz province to receive daily care. Census was used as sampling method $(\mathrm{n}=88)$. Ratio of response was 72.2 percent. A three-part questionnaire was used as data collection tool. Data were collected using the questionnaire. First part included demographic characteristics, second part contained 'basic need satisfaction questionnaire' by Haymes-Green, and third part included modified Barthel Scale. This scale was psychometrically evaluated in Iran and correlation between the respective version and original version of Barthel was reported as 0.99 .

\section{RESULTS}

Regarding basic needs satisfaction based on Maslow's pyramid, mean of three dimensions (physiologic, support, and attachment) was higher than average. Highest mean of basic needs satisfaction was related to physical dimension and lowest mean was related to support dimension. Regarding independent daily functioning, lowest frequency was related to complete independence in performing daily function in "climbing stairs" followed by "urinary control".

\section{CONCLUSIONS}

In investigation of basic needs satisfaction, mean scores of all dimensions was higher than average. Majority of the elderly people has low dependence on others' help, or they were completely independent.

HOW TO CITE THIS ARTICLE: Sharifi S, Safabakhsh L, Khojasteh F. Investigating basic needs satisfaction in the elderly people with some individual characteristics based on modelling and role-modelling theory. J. Evolution Med. Dent. Sci. 2019;8(21):1751-1754, DOI: $10.14260 /$ jemds/2019/384

\section{BACKGROUND}

Modeling and role modeling theory is one of the applied theories in nursing, which originates from the practice. This is a client-oriented theory. Understanding the client or his model of the world is the basis of nurse-client's interaction. Maslow's hierarchy of needs is used in this theory as the framework of basic needs satisfaction. Human beings inherently need to turn their potential capabilities into the real ones. If the basic human needs are not met, the human will not grow. Satisfying basic needs is not only one of the concepts in this theory, but also it is actually the core concept of this model.

Theorists of this theory believe that when basic needs are met and dependence is developed in the individual, he will be able to adapt with the stresses, feel valuable, and mobilize

'Financial or Other Competing Interest': None.

Submission 24-01-2019, Peer Review 10-05-2019,

Acceptance 17-05-2019, Published 27-05-2019.

Corresponding Author:

Leila Safabakhsh,

Community Nursing Research Center,

Zahedan University of Medical Sciences,

Zahedan, Iran.

E-mail: leilasafabakhsh@gmail.com

DOI: $10.14260 / \mathrm{jemds} / 2019 / 384$

\section{(c) (1) $(9)$}

resources for coping with stresses. While if basic needs are not met and confident dependence is not developed in the person, the ability and mobilization of resources for stress coping would be reduced.[1] In a study by Acton (1993), based on the theory of Erickson et al., basic needs satisfaction was the main predictor of well-being status of care providers for Alzheimer patients, and the total model described 49 percent of variance of care providers' well-being.[2] Barnfather (1993) reported that there is relationship between basic needs satisfaction and potential adaptation status. Individuals that their four basic needs (Out of four) were met, they have been in more balanced state in terms of adaptation and none of them was in impoverishment stage, where one is not able to cope with stress. ${ }^{[3]}$ Although according to various theories, human being passes different stages during his life, elderly period is especially important because of some physiologic changes that naturally occur by aging, including death of spouse, independence of children, retirement, etc. considering changes in age conditions in this period, meeting basic needs may be more dependent on others, and the probability for lack of basic needs satisfaction, and its adverse consequences are more highlighted.

Today the human communities face a great challenge known as increasing population of the elderly, due to health improvements and reduced births and deaths. By 2025 there 
will be over 700 million people over the age of $60 .{ }^{[4]}$ In Iran, it is predicted that more than 26 million seniors over 60 years old will live in Iran by 2050.[5]

The important issue of health care systems in the elderly is to maximize the health of this age group. Blazer et al. (2005) conducted a study aiming at determining relationship between variables of "non-satisfaction of basic needs", "culture" and "race" in predicting the likelihood of mortality in the elderly. In this study, which was conducted in control and case group over a 10-year period, it was revealed that nonsatisfaction of basic needs (adequate income, housing status and neighbors) was a significant predictor of the probability of mortality in the elderly $(\mathrm{p}<0.0001) .[6]$

Levi et al. (2002) conducted a research on 600 individuals over 23 years. They reported that individuals with more positive perception of their elderly have longevity 7.5 times more than individuals with less positive attitude in this regard. [7]

Long et al. (2002) in a longitudinal study on 737 elderly people reported that experience of out-of-home work was the only predictor of death among various social variables. Housewife women had a higher risk of death by 3.5 times, while this variable led to 2.7 change in variance in employed women (In case of fixed state for other variables). ${ }^{[8]}$ Balfour and Kaplan (2002) in their work on elderly people reported that the environment and neighbors might influence functional health of people in elderly period. The problems that were reported included as follows: Traffic, noise, crimes, garbage, light, and public transportation. Individuals with these problems in their neighborhood were at higher risk of losing functional health.[9]

Since number of elderly people in the country is rising and given that, no study based on model of Erickson, Tomlin and Swain was found in the library studies in Iran, current research was conducted aiming at investigating basic needs satisfaction and some individual characteristics in elderly people.

\section{METHODS}

This is a descriptive research type. The research population in this descriptive research included all elderly people referring to Kahrizak Charity Institute in Alborz province to receive daily care. Census was used as sampling method ( $\mathrm{n}=88$ ). Following gaining approval of head of Kahrizak Institute in Alborz province, the researcher referred to the daily elderly care center and explained the research. In case of consent of elderly people, they entered the study. In addition, the researcher explained that they can leave empty any question that they do not like to answer. None of elderly people referring to the daily care center rejected to participate in the research. 64 elderly people took part in the research. Other cases were related to absence of elderly people or nonreferring to the daily care center. Response rate was 72.2 percent.

Data were collected using the questionnaire. First part included items about some demographic characteristics, such as age, gender, education, insurance status, and external support sources like family, friends, and relatives. Second part contained 'basic need satisfaction questionnaire' by Haymes \& Green, which was designed based on Maslow's theory. The questionnaire consists of 12 items in three areas of physiological (4 items), security (4 items), and affiliation and attachment (4 items), which is measured by the five-point Likert scale (Completely agree to completely disagree). Cronbach Alpha coefficient was calculated in order to determine the reliability of the internal consistency, and it was obtained as 0.71.4. The third part included modified Barthel Scale. It is used for investigating functional state of elderly people which includes 10 parts (Fecal control, urinary control, toilet use, feeding, transfer, wheelchair/walking, climbing stairs, dressing, bathing, and grooming). The score between 0 - 20 denoted total dependence, 21 - 60 denoted severe dependence, 61 - 90 denoted average dependence, and 91 - 99 implied low dependence, and sore 100 showed total independence. This scale was psychometrically evaluated in Iran and correlation between the respective version and original version of Barthel was reported as 0.99. Its concurrent validity was also supported. ICC in relation to the whole tool was obtained as 0.998 . Coefficient of internal stability was calculated as 0.96-0.99.[10]

Statistical analysis was performed with SPSS software version 16 at $95 \%$ confidence level and estimate error of 0.05 . Descriptive statistics were used for data analysis.

\section{RESULTS}

Women constituted majority of research population (64.5\%). Their age range was $60-86$ years $(71 \pm 6.52)$. Majority of elderly people were married, and their spouse were alive (59.4\%). 76.4 percent of elderly people were insured, and 37.1 percent were covered by supplementary insurance. Majority of elderly people were illiterate (60.9\%). Most of participants stated that "their children would support them in case of difficulties' (43.8\%). 29.7 percent of elderly people had more than one source of support, and 6.2 percent expressed that they do not have any source of support in case of problems (Table 1). Majority of elderly people lived with their spouse and children (61\%) and 18.8 percent lived alone. 84.3 percent of participants were satisfied with social services provided for the elderly people. Regarding satisfaction of basic needs based on Maslow's hierarchy of needs, mean of all dimensions (Physiologic, support, and attachment) was higher than average. Highest mean of basic needs satisfaction was related to physical dimension $(4.56 \pm 0.62)$ and lowest mean was related to support dimension $(3.82 \pm 0.96)$ (Table 2). Responses to the items related to personal affairs are separately given in Table 3 . The table suggests that lowest frequency in relation to complete independence in daily task functioning is related to "climbing stairs" followed by "urinary control". Mean score of modified Barthel index was $93.14 \pm$ 11.35 (Range at 0-100). Score of 39.06 percent of participants was between 61-90 (Average dependence), 91-99 in 35.94 percent (Mild dependence), and 100 in 25 cases of participants (Complete independence) (Table 3). 


\begin{tabular}{|c|c|c|}
\hline \multicolumn{2}{|r|}{ Variable } & No. (\%) \\
\hline Age & $\begin{array}{c}70> \\
80-70 \\
80<\end{array}$ & $\begin{array}{c}33(52.4 \%) \\
24(37.5 \%) \\
6(9.4 \%)\end{array}$ \\
\hline Gender & $\begin{array}{c}\text { Female } \\
\text { Male }\end{array}$ & $\begin{array}{l}40(64.5 \%) \\
22(35.5 \%)\end{array}$ \\
\hline $\begin{array}{c}\text { Are you } \\
\text { insured? }\end{array}$ & $\begin{array}{c}\text { Yes } \\
\text { No } \\
\text { I don't know }\end{array}$ & $\begin{array}{c}49(76.6 \%) \\
14(21.9 \%) \\
1(1.6)\end{array}$ \\
\hline Education & $\begin{array}{c}\text { Illiterate } \\
\text { High school and diploma } \\
\text { Religious education }\end{array}$ & $\begin{array}{l}39(60.9 \%) \\
18(28.2 \%) \\
7(10.9 \%)\end{array}$ \\
\hline $\begin{array}{l}\text { Who would } \\
\text { support you } \\
\text { in case of } \\
\text { difficulties? }\end{array}$ & $\begin{array}{c}\text { My spouse } \\
\text { My children } \\
\text { My spouse and children } \\
\text { Friends and relatives } \\
\text { No one }\end{array}$ & $\begin{array}{c}7(10.9 \%) \\
28(43.8 \%) \\
19(29.7 \%) \\
6(9.4 \%) \\
4(6.2 \%)\end{array}$ \\
\hline $\begin{array}{l}\text { To whom } \\
\text { are you } \\
\text { financially } \\
\text { dependent? }\end{array}$ & $\begin{array}{c}\text { Retirement pension Children's aid } \\
\text { Welfare organization/ Imam Khomeini Relief } \\
\text { Organization/ Others } \\
\text { Retirement pension and other aids }\end{array}$ & $\begin{array}{c}(35.9 \%) \\
(17.2 \%) \\
23(35.9 \%) \\
7(10.9 \%)\end{array}$ \\
\hline $\begin{array}{l}\text { Marital } \\
\text { status }\end{array}$ & $\begin{array}{l}\text { Married } \\
\text { Widow }\end{array}$ & $\begin{array}{l}38(59.4 \%) \\
26(40.6 \%)\end{array}$ \\
\hline $\begin{array}{l}\text { With whom } \\
\text { are you } \\
\text { currently } \\
\text { living? }\end{array}$ & $\begin{array}{l}\text { My spouse and children } \\
\text { My children } \\
\text { Alone }\end{array}$ & $\begin{array}{c}39(61 \%) \\
13(20.3 \%) \\
12(18.8 \%)\end{array}$ \\
\hline \begin{tabular}{|c|} 
Are you \\
satisfied with \\
social care \\
services \\
provided for \\
elderly \\
people?
\end{tabular} & $\begin{array}{c}\text { Yes } \\
\text { No } \\
\text { No idea }\end{array}$ & $\begin{array}{c}54(84.3 \%) \\
1(1.6 \%) \\
9(14.1 \%)\end{array}$ \\
\hline $\begin{array}{r}\text { Table 1. DeI } \\
\mathrm{Ka}\end{array}$ & $\begin{array}{l}\text { mographic Characteristics of the Elderly } R \\
\text { hrizak Daily Care Center in Alborz Provin }\end{array}$ & $\begin{array}{l}\text { eferring to } \\
\text { e }\end{array}$ \\
\hline
\end{tabular}

\begin{tabular}{|c|c|}
\hline Dimensions of basic needs' & Mean (SD) \\
satisfaction & $4.56(0.62)$ \\
Physical dimension (4 items) & $3.82(096)$ \\
Support dimension (4 items) & $4.03(1)$ \\
Attachment dimension (4 items) & \\
\hline Table 2. Dimensions of Basic Needs' Satisfaction in the Elderly \\
Referring to Kahrizak Daily Care Center in Alborz Province \\
\hline
\end{tabular}

\begin{tabular}{|c|c|c|c|}
\hline Index Item & Score & Frequency & $\mathrm{SD} \pm$ Mean \\
\hline \multirow{3}{*}{ 1. Bowel control } & 5 & 1 & \multirow{3}{*}{$0.67 \pm 9.89$} \\
\hline & 8 & 1 & \\
\hline & 10 & 62 & \\
\hline \multirow{4}{*}{ 2. Bladder control } & 2 & 3 & \multirow{4}{*}{$2 \pm 8.86$} \\
\hline & 5 & 3 & \\
\hline & 8 & 17 & \\
\hline & 10 & 41 & \\
\hline \multirow{2}{*}{ 3. Toilet transfers } & 8 & 4 & \multirow{2}{*}{$0.49 \pm 9.87$} \\
\hline & 10 & 60 & \\
\hline \multirow{3}{*}{ 4. Feeding } & 5 & 1 & \multirow{3}{*}{$1.02 \pm 9.45$} \\
\hline & 8 & 15 & \\
\hline & 10 & 48 & \\
\hline 5. Chair/bed transfers & 15 & 64 & $0.00 \pm 15$ \\
\hline \multirow{2}{*}{ 6. Ambulation } & 12 & 2 & \multirow{2}{*}{$0.53 \pm 14.91$} \\
\hline & 15 & 62 & \\
\hline \multirow{3}{*}{ 7. Dressing } & 5 & 1 & \multirow{3}{*}{$810 . \pm 9.77$} \\
\hline & 8 & 5 & \\
\hline & 10 & 58 & \\
\hline \multirow{3}{*}{ 8. Stair climbing } & 0 & 12 & \multirow{3}{*}{$4.26 \pm 5.91$} \\
\hline & 2 & 14 & \\
\hline & 5 & 4 & \\
\hline
\end{tabular}

\begin{tabular}{|c|c|c|c|}
\hline & 8 & 5 & \\
\hline & 10 & 29 & \\
\hline \multirow{3}{*}{$\begin{array}{l}\text { 9. Personal hygiene } \\
\text { (Grooming) }\end{array}$} & 1 & 1 & \multirow{3}{*}{$540 . \pm 4.89$} \\
\hline & 4 & 3 & \\
\hline & 5 & 60 & \\
\hline \multirow{5}{*}{ 10. Bathing } & 0 & 1 & \multirow{5}{*}{$1.03 \pm 4.59$} \\
\hline & 1 & 2 & \\
\hline & 3 & 4 & \\
\hline & 4 & 5 & \\
\hline & 5 & 52 & \\
\hline Total score & \multicolumn{3}{|c|}{$11.35 \pm 93.14$} \\
\hline \multicolumn{4}{|c|}{$\begin{array}{c}\text { Table 3. Barthel Index Dimensions in the Elderly Referring to } \\
\text { Kahrizak Daily Care Center in Alborz Province }\end{array}$} \\
\hline
\end{tabular}

\section{DISCUSSION}

Regarding basic needs satisfaction based on Maslow's pyramid of needs, mean of three dimensions (Physiologic, support, and attachment) was higher than average. 21.9 percent of the elderly in this study were not covered by any kind of insurance, which is significant due to the occurrence of many diseases and their costs in the elderly period. In addition, only 37.1 percent of the elderly had supplement insurance. In the study by Matsui and Capezuti (2008), rate of medical care insurance for the American elderly population was reported to be 83 percent.[11] In addition, 79.2 percent enjoyed the health insurance and 20.8 percent of the elderly had long-term care insurance. Only 4 percent of the elderly had no one to support them in case of the problems, which indicates a high level of family support in the elderly community in the study. Unfortunately, in the absence of family and social support, the health care provider does not provide long-term and home care services for the elderly. Although the number of people who do not have any family and social support is small, but with an increase in the percentage of the elderly in the community and in the macro scale, this would be significant. 60.9 percent of the elderly were illiterate, and this illiteracy can Increase risk of non-compliance with the rights of the elderly. Arab et al. (2009) in their study aiming at determining patient rights compliance in hospitals affiliated to Tehran University of Medical Sciences reported that patients' awareness of their rights increase by increasing education level.[12]

Disability score was $93.14 \pm 11.35$ in the current research. Disability score in the study by Tagharobi et al. was $68.56 \pm$ 37.04. Jalali (2008) studied a group of children and young adults with low-grade glioma treated with stereotactic conformal radiotherapy before and after radiotherapy. Disability score was reported as $94 \pm 7.8$, and it was reported as $97.7 \pm 7.8$ and $99.00 \pm 1.94$, respectively 6 months and 3 years after initiation of treatment. [13] In the study by Morton et al. (2008) on a group of elderly people in Australia, mean score of stability was reported as $63.8 \pm 23.1$.[14] It is clear that factors such as age, diseases, nature of disease, its progress, medical and rehabilitation measures are involved in developing differences.[10] Regarding satisfaction of basic needs based on Maslow's hierarchy of needs, mean of all dimensions (Physiologic, support, and attachment) was higher than average. In fact, satisfying basic needs of the research population was at relatively optimal level. Ojha and Pramanick (2008) in their study entitled "Effects of Age on Intensity and Priority of Life Needs" reported that the age has significant effects on all dimensions of basic needs. Physical, security, and attachment needs increase in all individuals by getting older. So that needs were $(21.40,13.73,22.20)$ in "young elderly 
people" (61-70) and (22.37, 14.47, 22.96) in "old elderly people" (71-80).[15] Mean score of attachment and security feeling was higher in old elderly group than other age ranges. According to various studies, non-satisfaction of basic needs in the elderly people facilitates their death. Based on the theory of Erickson et al, which Maslow's hierarchy of needs is its core, the individuals that their basic needs are met at higher levels are more capable to cope with the living stressors. They are able to achieve balance. While individuals with higher levels of unsatisfied basic needs are less capable to mobilize their resources to cope with stress. In fact, when they face the stressors, they are at risk. [7]

\section{CONCLUSIONS}

Most of the elderly were covered by insurance and support system. Most of the elderly people in the current study were young elderly (below 70), and mean score of physical support, and attachment dimensions was higher than average. Majority of the elderly people has low dependence on others' help, or they were completely independent.

\section{Recommendations}

Considering that some elderly people in this work were not covered by the insurance and given increased incidence of diseases in this group, it is suggested that insurance conditions are facilitated for all people above 60 years old. In addition, individuals with poor social and family support, or those without such support are identified and supported by public or private support systems. Since illiteracy level is generally high among the elderly, this group is more vulnerable in terms of non-compliance of client rights, and health personnel should be aware of this fact and inform them regarding their rights.

\section{ACKNOWLEDGEMENT}

The study is approved By Research Committee of Zahedan University of Medical Sciences and the code of ethics is IR.ZAUMS.REC.1397.34

All elderly people who took part in this research are highly appreciated. Dr. Tagharobi and her colleagues are appreciated for providing the scoring for Barthel index. The researchers acknowledge all authorities in Kahrizak Charity Institute in Alborz province.

\section{REFERENCES}

[1] Peterson SJ, Bredow TS. Middle range theory: application to nursing research. Philadelphia: Lippincott Williams and Wilkins 2004.

[2] Barnfather JS, Ronis DL. Test of a model of psychosocial resources, stress and health among undereducated adults. Research in Nursing \& Health 2000;23(1):5566.

[3] Barnfather JS. Testing a theoretical proposition for modeling and role modeling: basic need and adaptive potential status. Issues in Mental Health Nursing 1993;14(1):1-18.

[4] Noroozian M. The elderly population in Iran: an ever growing concern in the health system. Iranian Journal of Psychiatry and Behavioral Sciences 2012;6(2):1-6.

[5] Amini R, Ingman SR, Sahaf R. Aging in Iran: past, present and future. The Journal of Aging in Emerging Economies 2013;4(1):17-34.

[6] Blazer DG, Sachs-Ericsson N, Hybels CF. Perception of unmet basic needs as a predictor of mortality among community-dwelling older adults. Am J Public Health 2005;95(2)299-304.

[7] Levy BR, Slade MD, Kunkel SR, et al. Longevity increased by positive self-perceptions of aging. J Pers Soc Psychol 2002;83(2):261-70.

[8] Long JA, Ickovics JR, Gill TM, et al. Social class and mortality in older women. J Clin Epidemiol 2002;55(10):952-8.

[9] Balfour JL, Kaplan GA. Neighborhood environment and loss of physical function in older adults: evidence from the Alameda County Study. Am J Epidemiol 2002;155(6):507-15.

[10] Tagharrobi Z, Sharifi K, Sooky Z. Psychometric evaluation of Shah Version of modified Barthel index in elderly people residing in Kashan Golabchi nursing home. Feyz 2011;15(3):213-24.

[11] Matsui M, Capezuti E. Perceived autonomy and selfcare resources among senior center users. Geriatric Nursing 2008;29(2):141-7.

[12] Arab M, Zarei A, Hosseini M. Awareness and observation of patients' rights from the perspective of patients: a study in university hospitals in Tehran. Journal of School of Public Health and Institute of Public Health Research 2010;8(2):77-86.

[13] Jalali R, Dutta D, Kamble R, et al. Prospective assessment of activities of daily living using Modified Barthel's Index in children and young adults with lowgrade gliomas treated with stereotactic conformal radiotherapy. J Neuro-Oncol 2008;90(3):321-8.

[14] De Morton NA, Keating JL, Davidson M. Rasch analysis of the Barthel index in the assessment of hospitalized older patients after admission for an acute medical condition. Arch Phys Med Rehabil 2008;89(4):641-7.

[15] Ojha H, Pramanick M. Effects of age on intensity and priority of life needs. Journal of the Indian Academy of Applied Psychology 2009;35(1):131-6. 